María Laura Montemurro, La Santa Ana Triple en el Museo Nacional de Bellas Artes de Buenos Aires: una propuesta interpretativa

\title{
La Santa Ana Triple en el Museo Nacional de Bellas Artes de Buenos Aires: una propuesta interpretativa
}

\section{Anna Seldbritt at the National Museum of Fine Arts in Buenos Aires: a new interpretative proposal}

\author{
María Laura MONTEMURRO \\ CONICET-UBA-UNGS \\ lauramontemurro@gmail.com
}

Recibido: 20/03/2015

Aceptado: 01/05/2015

Resumen: El Museo Nacional de Bellas Artes conserva entre su patrimonio de esculturas antiguas y medievales, una talla alemana del siglo XVI que representa a Santa Ana con la Virgen y el Niño. Esta iconografía conocida como Santa Ana Triple, o Anna Selbdritt en alemán, adquiere mucha popularidad en el norte de Europa. La lectura más corriente sobre esta iconografía interpreta las figuras de María y el Niño como atributos de Ana. Sin embargo, las particularidades en la representación de las figuras de Ana y María en ésta y otras tallas semejantes dejan, a nuestro juicio, una serie de cuestiones sin considerar. A partir de estas observaciones, el presente artículo propone una nueva lectura basada principalmente en la ausencia de rasgos de vejez en la representación de Santa Ana así como en las ambigüedadades presentes en la efigie de María.

Palabras clave: Santa Ana Triple, Anna Selbdritt, Escultura, Edad Media, Vejez, Museo Nacional de Bellas Artes de Buenos Aires

Abstract: Amidst the ancient and medieval sculptures preserved at the National Museum of Fine Arts in Buenos Aires, there is a $15^{\text {th }}$. Century German wood carving of St. Anne with the Virgin Mary and the Child. This iconography, known in Germany as Anna Selbdritt, achieved a great measure of popularity in Northern Europe during the last years of the Middle Ages. The prevailing interpretation of this iconographic type regards Mary and the Child as attributes of St. Anne. However, the peculiarities of the rendering of Anne and Mary in this, and other, similar carvings, open in our view a series of issues for consideration. Departing from these observations, this paper proposes a new interpretation, mainly supported in the rather youthful image of St. Anne, as well as in some ambiguities in that of Mary.

Key words: Virgin and Child with Saint Anne, Anna Selbdritt, Sculpture, Middle Ages, Old Age, National Museum of Fine Arts in Buenos Aires

Sumario: 1. Introducción. 2. El surgimiento de la "parentela sagrada". 3. Santa Ana y la Virgen: representación, interacción e interpretación. 4. Conclusión. Fuentes y Bibliografía. 
María Laura Montemurro, La Santa Ana Triple en el Museo Nacional de Bellas Artes de Buenos Aires: una propuesta interpretativa

\section{Introducción}

En 1971 el Museo Nacional de Bellas Artes de Buenos Aires recibió una donación de la fundación Di Tella ${ }^{1}$. La misma consistía en cuarenta obras de arte donde se incluían artistas argentinos, iberoamericanos y una serie de obras antiguas. Entre estas últimas se encontraba una Santa Ana con la Virgen y el Niño ${ }^{2}$ catalogada como procedente del sur de Alemania y datada hacia principios del siglo XVI (fig.1 y 2). Este tipo de composición, conocido como Anna Selbdritt en alemán, o la Santa Ana Triple en español, comenzó a hacerse popular con el crecimiento del culto a Santa Ana. Éste llega a su máxima expresión ente los años 1470 y 1530 especialmente en el norte de Europa, si bien también se encuentran manifestaciones del culto en otros lados ${ }^{3}$.

Lamentablemente la talla se encuentra bastante deteriorada. Faltan ambos brazos de la Virgen y el brazo derecho y mano izquierda del Niño. La iconografía es simple: Santa Ana, de pie, sostiene con su brazo derecho al Niño Jesús y con el izquierdo, sin ningún esfuerzo aparente, a una Virgen de tamaño reducido. Sus ropas están acordes con las que usaría una mujer casada o una viuda ${ }^{4}$, comprendiendo un vestido con un alto cinturón, griñón y manto cuyos grandes y pesados pliegues otorgan cierto ritmo a la composición restándole monotonía.

Ningún rasgo físico en la figura de Santa Ana denuncia su condición de mujer madura. Sólo el griñón podría permitir inferir este dato, además del hecho, por supuesto, de ser la abuela de Cristo. La Virgen esta coronada y lleva un vestido ajustado como el de su madre, con un cinturón. Su pequeño cuerpo gira para enfrentar a su hijo que en cambio, está representado de una forma más naturalista, como un bebé, sin ropas.

\footnotetext{
${ }^{1}$ El Ingeniero Torcuato Di Tella fue un industrial de origen italiano que llegó a la Argentina a la edad de trece años. En 1911 crea una amasadora de pan que tuvo enorme éxito y derivó en la fundación de la empresa Sección Industrial Amasadoras Mecánicas (SIAM). Di Tella da inicio a su colección de arte compuesta por pintura, fotografías y esculturas adquiridas en el país y en el extranjero. Tras su fallecimiento la misma es continuada por su hijo quien en 1958 funda la Fundación Di Tella con el fin de promover empresas de carácter cultural.

${ }^{2}$ Alemania, comienzos del siglo XVI, madera con restos de policromía, 120 x 38 x 23,5 cm.

${ }^{3}$ Según Virginia Nixon se encuentran en gran numero en Escandinavia, España, Francia, Polonia y otras partes de Europa del Este, en menor número en Italia y aun en menor cantidad, en Inglaterra. NIXON, Virginia 2004: 162.

${ }^{4}$ Especialmente el uso del griñón, aunque no era exclusivo de las viudas. Ver, por ejemplo, el comentario sobre esta prenda en VIOLLET LE DUC, Eugene 1858: 428.
} 
María Laura Montemurro, La Santa Ana Triple en el Museo Nacional de Bellas Artes de Buenos Aires: una propuesta interpretativa

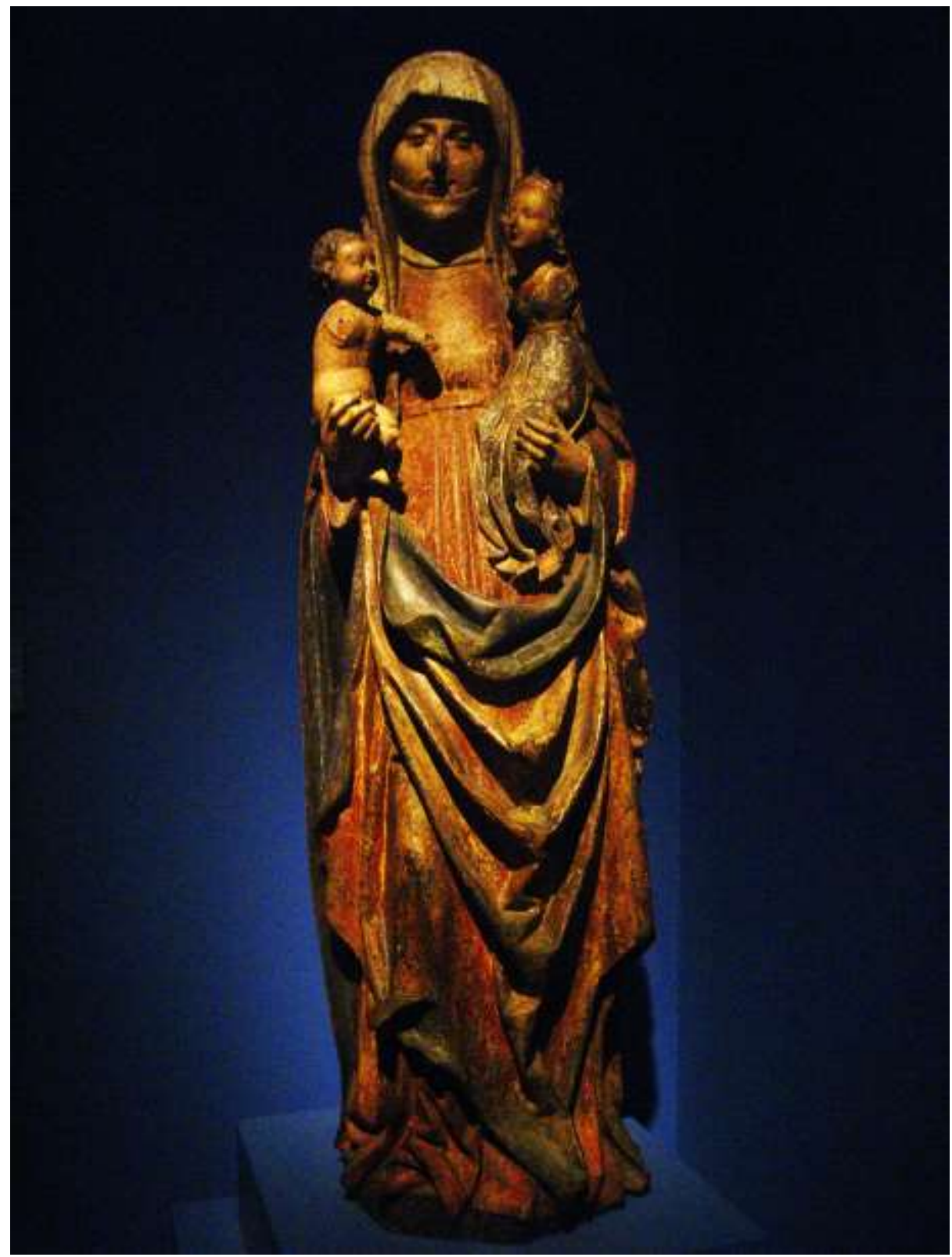

Fig. 1. Santa Ana con la Virgen y el Niño. Museo Nacional de Bellas Artes, Buenos Aires. Foto: Clelia Pizerchia

A causa de los miembros faltantes es difícil reconstruir la imagen en su totalidad. La comparación con imágenes semejantes puede, al menos, darnos una idea de cuales pudieron haber sido los gestos de ambas figuras, facilitándonos la comprensión del conjunto. Distintos ejemplos de esta misma iconografía coinciden en representar cierta interacción entre las figuras más pequeñas. En cambio, Ana suele mantener una mirada frontal, algo distante y casi indiferente a lo que hace su descendencia. En muchos casos, incluyendo las representaciones de Ana sedente, se repiten estas características. Por el contrario, María y el Niño por lo general interactúan de alguna manera, ya sea sosteniendo un libro o, en el caso de que la 
María Laura Montemurro, La Santa Ana Triple en el Museo Nacional de Bellas Artes de Buenos Aires: una propuesta interpretativa

escultura sea un relicario, un cofre para reliquias ${ }^{5}$. En otros casos, si bien no hay contacto entre las figuras, hay una proximidad y cierta intimidad que se produce a partir del giro de los cuerpos.

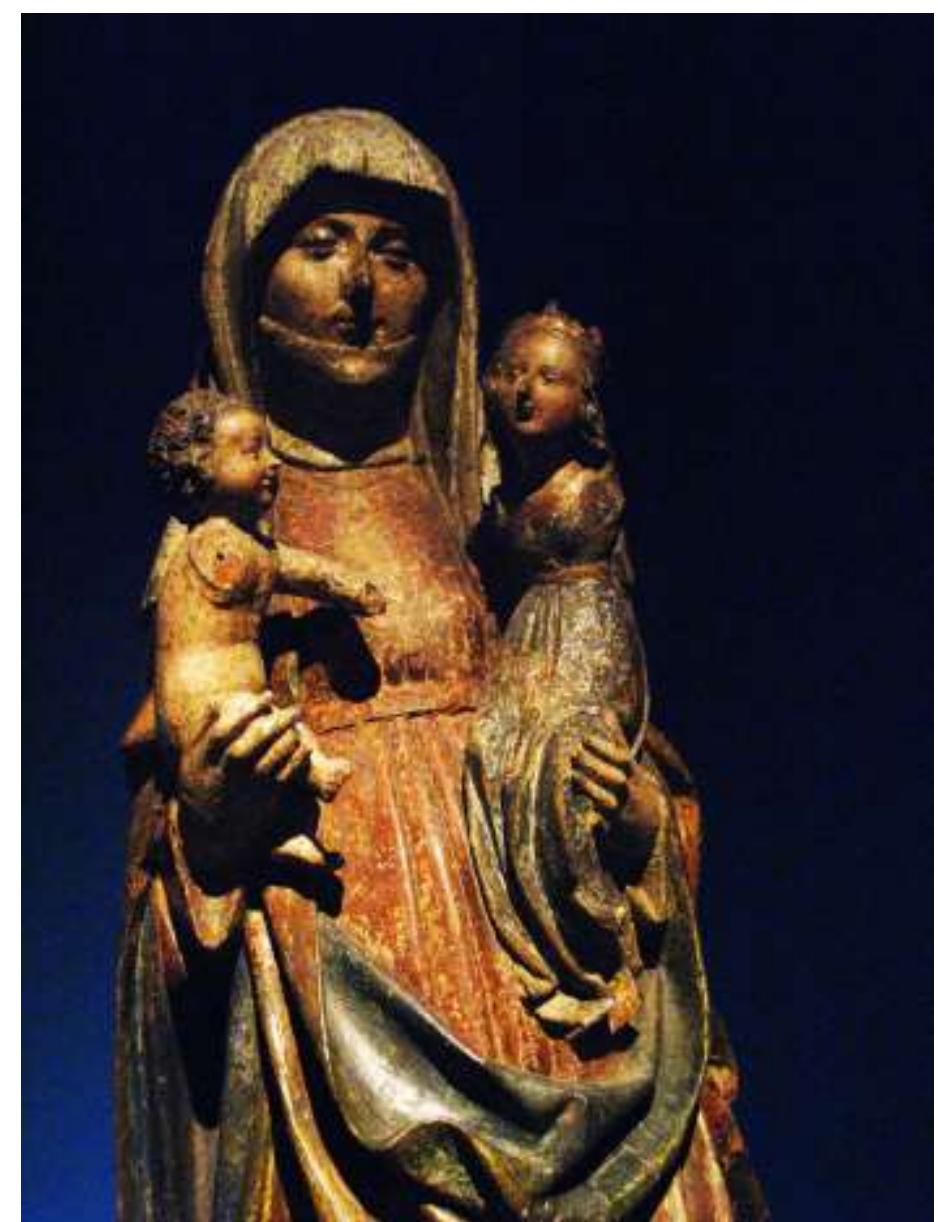

Fig. 2. Santa Ana con la Virgen y el Niño. Detalle. Foto: Clelia Pizerchia

Esto lo podemos observar en el caso del ejemplar del Museo Nacional ya que si bien las figuras están incompletas, ambas están enfrentadas y comparten un mismo espacio conectándose entre sí. Esta observación, al menos en el caso específico que aquí estamos estudiando, nos permite presentar ciertos reparos respecto a la teoría generalmente aceptada según la cual la Virgen y el Niño no serían más que atributos de Ana, siendo esta la figura fundamental de la composición. En el presente trabajo intentaremos ofrecer una lectura más compleja, donde la figura de Ana debe leerse en función de la de María y ésta, a su vez, en función de la del Niño. Esta lectura es reforzada por un segundo aspecto ambiguo en la composición: ¿es María representada como una mujer en miniatura o como una niña? El tamaño

${ }^{5}$ Así sucede, por ejemplo, en la escultura relicario de Hans Greiff (1472). Musée National du Moyen Âge, thermes et hôtel de Cluny, Paris. 
María Laura Montemurro, La Santa Ana Triple en el Museo Nacional de Bellas Artes de Buenos Aires: una propuesta interpretativa

corresponde al de una niña pero su figura es el de una mujer. Esta indeterminación se fortalece con la actitud juguetona con la que, en algunas representaciones, interactúa con su Hijo, más propia de una niña que de una joven. Esta ambigüedad será esencial a las lecturas de la imagen que propondremos en este trabajo.

\section{El surgimiento de la "parentela sagrada"}

El culto a Santa Ana se desarrolló tardíamente en el occidente medieval ${ }^{6}$. Los detalles relacionados con la concepción de María y que por ende involucran a su madre, fueron relatados originalmente en el protoevangelio de Santiago, un texto griego de c.150 aC y que posteriormente fue traducido al latín como el evangelio del Pseudo Mateo. El protoevangelio resolvía dos cuestiones de enorme importancia: la inmaculada concepción de la Virgen y el tema de los hermanos de Jesús mencionados en el Nuevo Testamento.

Con respecto al primer punto, éste queda aclarado cuando Ana recibe la noticia de su concepción por medio de un mensajero celeste, cuando su marido estaba ausente, dando a luz nueve meses más tarde. El segundo punto se resuelve diciendo que los mencionados hermanos de Jesús eran hijos de José por parte de un matrimonio anterior. Esto último fue sin embargo desmentido luego por San Jerónimo quien condenó los evangelios apócrifos de la niñez de Cristo. Según él, la palabra "hermanos" hacía referencia a los hijos de las hermanas de María. Esta interpretación fue posteriormente apoyada por otros teólogos y reelaborada en época carolingia. Así se conecta la creencia de que las tres Marías eran hermanas con el hecho de que Ana había tenido tres hijas, dando como resultado lo que se conoce como el trinubium: los tres casamientos de Ana. El primero, con Joaquín, fue el marco en el que nació la Virgen. Dado que una de las Marías se llamaba Cleofas, se dedujo que su padre debió llamarse así y éste fue el segundo esposo que Ana tomó después de haber enviudado. Siguiendo el mismo razonamiento, después de haber enviudado por segunda vez, Ana debió tomar como esposo a Salomé, de quien concibió a María Salomé. Esta leyenda dio origen a la iconografía conocida como La Parentela Sagrada donde se representa a la Virgen, Santa Ana y el Niño rodeados por las otras dos Marías y sus respectivos hijos. Una iconografía acotada del tema es el que representa solamente a los tres personajes centrales y que vemos representado en la talla del Museo Nacional.

\section{Santa Ana y la Virgen: representación, interacción e interpretación}

Entre las múltiples posibilidades de abordar el estudio de esta obra nos centraremos en un aspecto que, si bien es compartido por obras semejantes, aquí lo estudiaremos en referencia el ejemplar del Museo Nacional. Se trata de la ausencia

${ }^{6}$ Para lo que sigue ver NIXON 2004: 12 y stes. 
María Laura Montemurro, La Santa Ana Triple en el Museo Nacional de Bellas Artes de Buenos Aires: una propuesta interpretativa

de rasgos de vejez en Santa Ana y la transgresión del orden cronológico al representarse a la Virgen como una niña, junto a su hijo.

De acuerdo con el evangelio del Pseudo Mateo, desde el momento en que Ana y Joaquín contraen matrimonio hasta la partida de Joaquín y el anuncio de Ana por el ángel, debieron transcurrir poco más de veinte años. Por lo tanto, para el momento del nacimiento de Cristo, Ana debía rondar los cincuenta. Esta era la edad en la que, según los estándares medievales, una mujer entraba en la vejez ya que a partir de entonces no le era posible concebir ${ }^{7}$. Sin embargo, en las representaciones de Santa Ana Triple, especialmente las que pertenecen al periodo de mayor auge del culto, ésta prácticamente no presenta características físicas que delaten su edad. Esto es tanto más llamativo en cuanto tratamos con un estilo que comienza a caracterizarse por su realismo. En diferentes ejemplos del norte de Europa de fines de la Edad Media vemos que la vejez femenina es representada con características que apuntan al realismo y que a veces lo sobrepasan, convirtiéndose en obras satíricas (fig. 3).

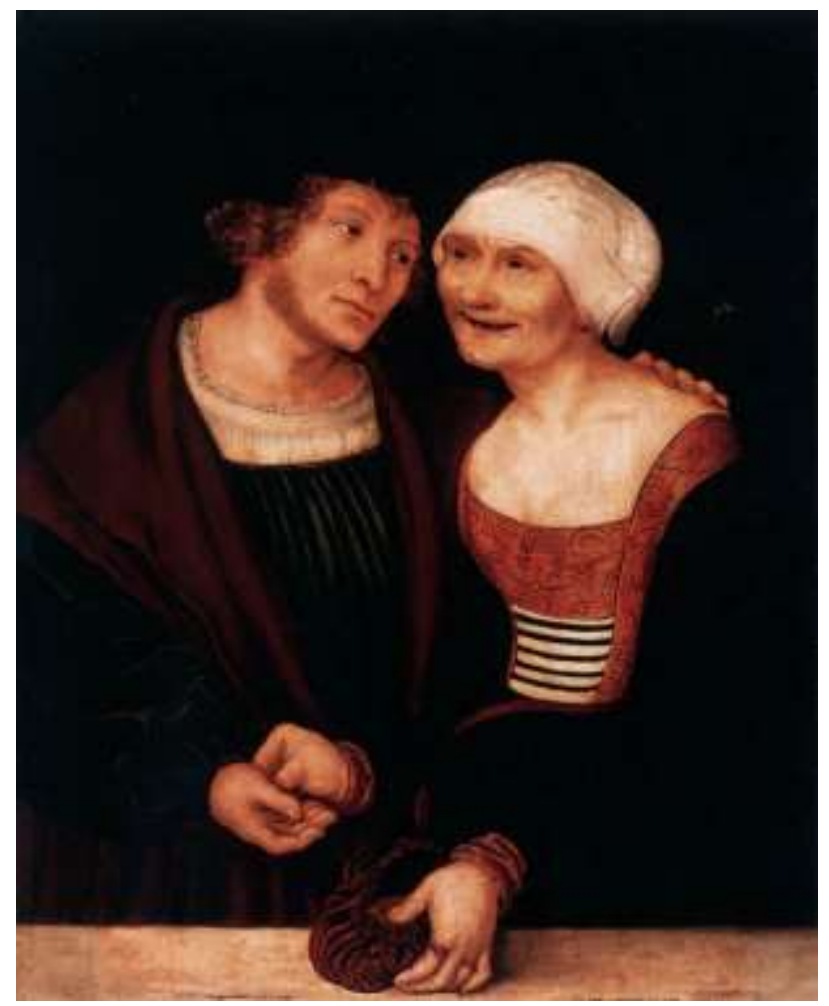

Fig. 3. Lucas Cranach El Viejo, Hombre joven con mujer vieja, 1420.

Fuente: Web Gallery of Art ( http://www.wga.hu)

\footnotetext{
${ }^{7}$ Según Vicente de Beauvais, al hablar de las seis etapas del hombre, establece el fin de la juventus a la edad de 50 años, cuando la mujer ya no puede concebir. Según la interpretación de Shulamith Shahar, si bien este autor se refiere al sexo masculino, al no existir en el hombre un marcador biológico claro que indique el fin de la juventud, se toma el de la mujer como índice para ambos. Ver SAHAR, Shulamith 1997: 19.
} 
María Laura Montemurro, La Santa Ana Triple en el Museo Nacional de Bellas Artes de Buenos Aires: una propuesta interpretativa

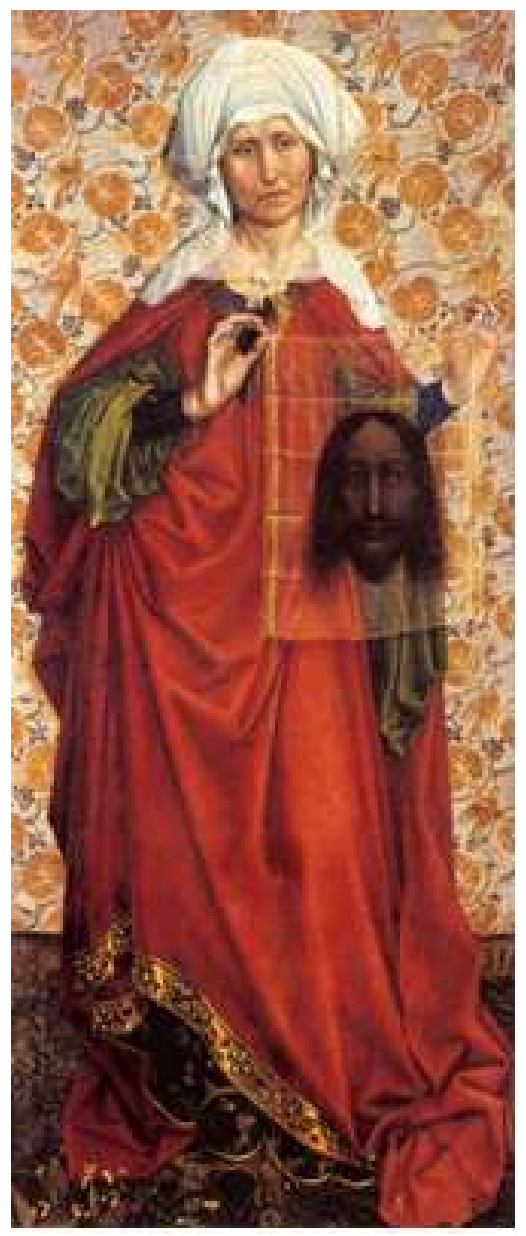

Fig. 4. Robert Campin, Santa Verónica, 1410.

Fuente: Web Gallery of Art (http://www.wga.hu)

Incluso personajes femeninos de la historia sagrada son representados con marcados signos de vejez cuando las fuentes escritas así los definen y en ocasiones, hasta cuando no (fig. 4). Incluso a la misma Santa Ana se la representa mostrando claros signos de madurez. El interrogante nace entonces de las imágenes de Santa Ana como la del MNBA, en las que su condición de mujer madura está representada solamente por el uso del griñón. Según Virginia Nixon, la representación de Ana como una mujer madura antes que anciana, es común a Alemania y Flandes. Esta autora propone que la reticencia a representar rasgos de vejez en Ana puede deberse a las connotaciones negativas asociadas a la imagen de la mujer anciana en la Alemania medieval. Pero también, sigue diciendo, podría querer señalar la continuidad de la fertilidad, característica esencial de la Parentela Sagrada y justificativo del trinubium ${ }^{8}$.

${ }^{8}$ NiXON 2204: 147. 
María Laura Montemurro, La Santa Ana Triple en el Museo Nacional de Bellas Artes de Buenos Aires: una propuesta interpretativa

Es muy factible que los signos de vejez sean obviados debido a la imagen negativa de la figura de la anciana. Como demuestra Gretchen Miezkowski ${ }^{9}$ éste era un topos literario, representante de todos los aspectos negativos adjudicados a la mujer enfatizados por el resentimiento de ya no ser atractiva a los ojos masculinos. Los prejuicios contra la mujer anciana estaban apoyados incluso por ideas surgidas del campo médico. Era común la creencia, de base aristotélica, de que la mujer era por naturaleza mucho más fría que el hombre y por lo tanto no tenía la capacidad de procesar la sangre de manera adecuada. Cuando la mujer no estaba embarazada, la sangre no procesada era expulsada, por eso la sangre menstrual se consideraba impura. Sin embargo, cuando la mujer llegaba a la menopausia, le era imposible deshacerse de ese veneno, volviéndose todavía más peligrosa.

Por otro lado, se consideraba en general que la vejez en el hombre traía consigo experiencia y sabiduría, pero cuando se trataba de la mujer este conocimiento estaba más bien ligado a las artes mágicas. Como da cuenta la autora antes citada, numerosos predicadores, panfletistas y moralistas, acusaban a la mujer anciana de hechicera y maga diciendo que "ellas controlan la fertilidad, la impotencia y los abortos y pueden preparar ruinosos filtros que atraen el amor"10. Aquella mujer que prepara filtros y pociones, que transgrede en definitiva las normas de la naturaleza, está reproduciendo en el exterior la mutación que tiene lugar en el interior de su organismo $^{11}$. Si bien estos prejuicios se aplicaban más bien a las mujeres pobres, es una posibilidad que hayan inhibido la representación de la vejez en Ana aunque, al parecer, ni siquiera ella pudo verse completamente liberada de este estereotipo. Su representación como hechicera fue sostenida por algunos académicos a propósito del grabado de Hans Baldung Grien, donde se la representa realizando una suerte de gesto encantatorio sobre los genitales del Niño ${ }^{12}$.

La vejez significaba cambio, transformación, transitoriedad. Todo aquello incapaz de mantener su naturaleza era asociado con el pecado. Roger Bacon lo había expresado de la siguiente manera: "el hombre malvado pierde su identidad, porque la identidad de una cosa consiste en retener su orden y preservar su naturaleza" 13 . El cambio entonces equivale a una pérdida de la identidad. Esta idea no se limita a la degeneración que puede ser causada por una enfermedad o deformidad. La vejez era otro motivo de cambio y quizás aún más terrible que la enfermedad debido a su universalidad. En este sentido, la vejez se presenta como síntoma del pecado universal y consecuencia de la caída. Era una creencia común que la humanidad

\footnotetext{
${ }^{9}$ MiEZSKOWSI, Gretchen 2007: 299-319.

${ }^{10}$ MIEZSKOWSKI 2007: 300.

${ }^{11}$ SAHAR 1996: 163.

${ }^{12}$ WIRTH, Jane 2003. Una interpretación diferente es propuesta por Denise Becker en BECKER 2005.

${ }^{13}$ BACON, Roger, Opus Majus VII.3.3.
} 
María Laura Montemurro, La Santa Ana Triple en el Museo Nacional de Bellas Artes de Buenos Aires: una propuesta interpretativa

había perdido la inmortalidad después del pecado original, siendo condenada a envejecer. Incluso, hay quienes pensaban que la extensión de la vida se había acortado todavía más después del diluvio ${ }^{14}$.

Por otro lado, para profundizar nuestro conocimiento sobre la representación de la vejez es necesario también atender a ciertos aspectos que conciernen a la actitud medieval frente a la corporalidad ${ }^{15}$. Es prácticamente un lugar común atribuir a la Edad Media una división dualista entre cuerpo y alma. El primero se percibe como foco de la debilidad y del pecado. La segunda, como la parte más pura del hombre y la más cercana a Dios. Sin embargo, recientemente diferentes autores han coincidido en señalar que esta división dualista no hace justicia a las distinciones más sutiles que la Edad Media hacía en realidad de las partes constitutivas del ser humano. ${ }^{16} \mathrm{Si}$ nos atenemos a la definición que San Agustín hace de la carne (caro) se comprende que es ella y no el cuerpo (corpus) donde residen las verdaderas consecuencias de la caída. En este sentido el cuerpo no consistiría tanto en la materia humana en sí misma. Se trataría, más bien de un organismo perfecto e íntegro al servicio del alma, con la que está armónicamente enlazado. Esta relación armónica queda, sin embargo, destruida por el pecado original. A partir de entonces la carne, sede de la concupiscencia, invade al cuerpo. Todo aquello, por lo tanto, que comúnmente adjudicamos al cuerpo: la transitoriedad, la decadencia, la decrepitud y finalmente la muerte no le pertenecen verdaderamente a él, sino a la carne. Si nos centramos en los debates sobre la Resurrección de los Muertos que con mayor o menor intensidad atravesaron la Edad Media, volveremos a encontrar esta distinción. ¿En qué consiste sino la promesa de la resurrección en cuerpo y alma si no es la de volver con un cuerpo "'transfigurado, restituido, como el de Cristo? ${ }^{17}$ Con esto en mente tal vez podamos aproximarnos al sentido de representar una Ana cuya santidad denota la restitución de un cuerpo íntegro, armónico y perfecto tal como le fuera dado al hombre antes de la caída y como el que volverá a poseer tras la resurrección. Por último, un cuerpo sin los signos de la decrepitud y del pecado habla de un alma pura. En este sentido vale la pena recordar que a partir del siglo XIII se afianza la

${ }^{14}$ SHAHAR 1996: 162. De acuerdo con el libro del Génesis, la edad promedio de los patriarcas antediluvianos superaba los 900 años. Adán, por ejemplo, vivió 960 años (Génesis 5:5), su hijo Set, 912 (Génesis 5:8) y Matusalén, 969 (Génesis 5:27).

${ }^{15} \mathrm{Si}$ bien es cierto que el modo de concebir las nociones de cuerpo y carne no permanecen inmutables a lo largo de todo el periodo medieval, las cuestiones que tocamos aquí con respecto a putrefacción y fragmentación nos parecen mantenerse bastante estables, incluso hacia la tardía Edad Media. Al respecto puede consultarse las siguientes obras: WALKER BYNUM 1996 y WALKER BYNUM 2011.

${ }^{16}$ Ver, por ejemplo, BIERNOFF, Suzannah 2002: 23-39.

${ }^{17}$ Sobre este tema ver WALKER BYNUM 1996. 
María Laura Montemurro, La Santa Ana Triple en el Museo Nacional de Bellas Artes de Buenos Aires: una propuesta interpretativa

tendencia a concebir al ser humano como una unidad donde cuerpo y alma estaban íntegramente conectados ${ }^{18}$.

Habiendo analizado la representación de Santa Ana, nos centraremos a continuación en el de la Virgen. Su cuerpo transgrede también, aunque de otra manera, el orden biológico. ¿Qué significa este cuerpo de niña-mujer? ¿Cómo leerlo en relación con la trascendencia de la vejez en el cuerpo de su madre?

Encontramos en la literatura religiosa del periodo el topos del niño-hombre. Esta figura trasciende tanto la decrepitud de la vejez como la ignorancia de la juventud encarnando en un cuerpo joven todos los aspectos positivos de la edad avanzada ${ }^{19}$. El niño-hombre es así sabio, templado y piadoso. Es la imagen encarnada por Daniel y Jesús en su infancia. En las Vitae de los santos, el niño-hombre encuentra su paralelo en la niña-mujer. Así, por ejemplo, Santa Catalina de Siena es descrita a la edad de seis años como poseedora de una "maravillosa madurez en sus cualidades y su conducta. Sus acciones no eran las de una niña ni los de una joven, sino que se inscribían en el espíritu de la edad avanzada" ${ }^{20}$. En el mismo tono se describe a la Virgen niña en el Evangelio del Pseudo Mateo:

"Y María causaba admiración en todo el mundo. A la edad de tres años, marchaba con paso tan seguro, hablaba tan perfectamente, ponía tanto ardor en sus alabanzas a Dios, que se habría tomado no por una niña pequeña, sino por una persona mayor, pues recitaba sus plegarias como si treinta años hubiera tenido. (...) Y se aplicaba a trabajar la lana, y lo que las mujeres adultas no sabían hacer, ella, en edad tan tierna, lo hacía a la perfección" ${ }^{21}$.

Si bien ésta idea nos brinda una posible interpretación a la contradictoria representación de María en la escultura del MNBA, creemos que posiblemente ésta encierre aún otro significado. Virginia Nixon se refiere a esta forma de representar a María como ejemplo de la ausencia de límites temporales precisos entre el pasado y presente por medio de lo cual el artista "pudo referirse simultáneamente al hecho de que ella es a la vez adulta (madre de Jesús) y niña (hija de Ana) ${ }^{22}$. La fluidez del tiempo en torno a la figura de Ana había sido ya remarcada por otros autores ${ }^{23}$ pero, ¿era necesario transgredir los límites temporales para remarcar la condición de María como hija? Quizás sí, pero hay otras cosas que pueden leerse en esta imagen y si bien la fertilidad de Ana puede ser una de ellas, creemos que hay otra aun más importante: la virginidad de María. Esta imagen de María niña recuerda a uno de los pocos casos en que la Virgen es representada de manera semejante: La Presentación

\footnotetext{
${ }^{18}$ Perkinson, Stephen 2009: 47. Ver también WALKER BYNUM 1996: 214-220.

${ }^{19}$ SHAHAR 1996: 172.

${ }^{20}$ SAHAR 1998: 48-49.

${ }^{21}$ El evangelio del Pseudo Mateo VI, 1.

${ }^{22}$ NIXON 2004:114.

${ }^{23}$ SAUTMAN, Francesca 1990: 73.
} 
María Laura Montemurro, La Santa Ana Triple en el Museo Nacional de Bellas Artes de Buenos Aires: una propuesta interpretativa

en el Templo, donde aparece como una mujercita en miniatura. Recordemos la descripción que diferentes evangelios apócrifos hacen de la entrada de María. Con la corta edad de tres años sube ella sola los quince escalones del templo, signo de precoz madurez y anuncio del milagro que se obraría en ella ${ }^{24}$. Esta representación ambigua de María, entre niña y mujer encarna más claramente la idea de su virginidad en un cuerpo sin historia, tal como se refiere Jocelyn Wogan-Browne respecto al cuerpo de la mujer virgen:

"La espiritualidad de la mujer casta reside, más bien, en cuerpos sin historia, ocultos del acontecimiento exterior y del cambio fisiológico. El ideal de la virginidad como la forma suprema de castidad obstruye el cuerpo históricos y biológico de las esposas, viudas, madres, que deben aspirar a un estado de virginidad representado en cuerpos sin periodos menstruales ni menopáusicos" ${ }^{25}$.

Si tomamos como factible que el cuerpo miniaturizado de María alude a su condición de virgen, entonces otras lecturas pueden desprenderse de este punto. Así como la figura de Ana debe ser leída en función de la de María, ésta debe interpretarse en función de la del Niño, porque si su virginidad en el momento de la concepción de Cristo no merecía ya ser discutida, la virginidad perpetua aparentemente aún era objeto de debate. El mismo Lutero escribe Daß Jesus ein Geborner Jude Sei (1523) en parte, para contestar las acusaciones que algunos le hacían de enseñar que María no permaneció virgen después del nacimiento de Cristo. La transgresión del orden cronológico al representar a María-niña junto con Cristo podría leerse entonces como la intención de mostrar a una María siempre virgen, pura como en sus días en el templo, aún después del nacimiento de su hijo.

La imagen puede, de este modo, ser leída como refuerzo del misterio de la Encarnación. La pureza de María se extiende al momento de su concepción, elevando así el estatus de su propia madre. La doctrina de la Inmaculada Concepción de la Virgen había estado lejos del consenso general durante gran parte de la Edad Media. Autores como Bernardo de Claraval rechazaban esta creencia. Sin embargo, y gracias en buena medida al impulso de los franciscanos, fue ganando terreno. En 1477, Sixto IV estableció la festividad de la Inmaculada Concepción. De esta manera logra establecerse un linaje sagrado que asegura la predestinación de María en el plan salvífico de Dios.

Está bien establecida la interpretación de la iconografía de la Santa Ana Triple, y especialmente de la Parentela Sagrada, como una manifestación de la humanidad de

\footnotetext{
${ }^{24}$ Evangelio de la natividad de María VI, I.

25 "Chaste female spirituality is, moroever, located in bodies without histories, locked away from outer event and physiological change. The ideal of virginity as the supreme form of chastity occludes the bodily history of biological wives, mothers, widows, who must aspire to the condition of a virginity imaged in bodies without menstrual and menopausal phases" (la traducción es nuestra). WOGAN-BROWNE, Jocelyn 1994: 24.
} 
María Laura Montemurro, La Santa Ana Triple en el Museo Nacional de Bellas Artes de Buenos Aires: una propuesta interpretativa

Cristo $^{26}$. Si, efectivamente, la representación aniñada de María alude a su condición de virgen, entonces se estaría alegando con claridad la doble naturaleza de Cristo, ya que el énfasis puesto en su condición humana, a partir de la representación de su linaje, no debería favorecerse en detrimento de su condición divina. María, si bien forma parte de la prueba de su humanidad, en su condición de virgen testimonia, por el contrario, la concepción divina. Tanto desde el aspecto espiritual como biológico, se fortalece así la imagen de María como continente sin mácula para dar a luz al hijo de Dios.

\section{Conclusión}

Virginia Nixon observa como factor común del culto a Santa Ana la atribución de una función salvífica ${ }^{27}$. Este atributo aparece, según la autora, recién en las hagiografías correspondientes a fines del siglo XV, no encontrándose en aquellas que son anteriores, como la Leyenda Dorada de Jacobo de la Vorágine. Esta función concuerda con el clima de ansiedad que parece vivirse en la Alemania de la tardía Edad Media respecto a la salvación individual, representada por la multiplicación de cofradías e indulgencias y que sería una preocupación esencial para Lutero y uno de los principales factores de motivación en su movimiento reformista. A diferencia de otros santos cuya intervención en la salvación era el de meros intermediadores, Ana ejercía esta facultad por sí misma. Es remarcable que esta función salvífica se le adjudique a una figura cuyo mérito consiste en estar asociada a Cristo meramente por la carne, especialmente en una época donde los lazos espirituales encuentran nuevas formas de expresión a partir de las cofradías y hasta suelen preponderar sobre los lazos carnales. Sólo tardíamente se trató de exaltar la figura de Ana, ubicándola en el comienzo del plan salvífico de Dios, justificando así su lugar como madre de la portadora de Cristo desde el comienzo de los tiempos ${ }^{28}$. En este sentido quizás se pudiese pensar, como Pamela Sheingorn sugiere al pasar, que una de las ideas que se manifiesta en la iconografía de la Santa Ana triple es la designación por parte de Dios de esta línea femenina desde el inicio de la creación.

Sin embargo, el auge del culto a la Santa no durará mucho y en conjunto con su declive se observan algunos cambios en la representación de Ana. No solamente su figura se va apartando del espacio central en las escenas de la Parentela Sagrada sino que sus características de mujer madura van dejando lugar a rasgos de anciana como

\footnotetext{
${ }^{26}$ Por ejemplo, SHEINGORN, Pamela 1990: 169-198.

${ }^{27}$ NIXON 2004: 42.

${ }^{28}$ Por ejemplo en la anónima Legenda Sanctae Annae, publicada por primera vez en Louvain, 1496.
} 
María Laura Montemurro, La Santa Ana Triple en el Museo Nacional de Bellas Artes de Buenos Aires: una propuesta interpretativa

lo ilustra, por ejemplo, un grabado de Lucas Van Leyden ${ }^{29}$ o un ejemplo bastante más tardío de Dirk Van Hoogstraten (fig. 5).

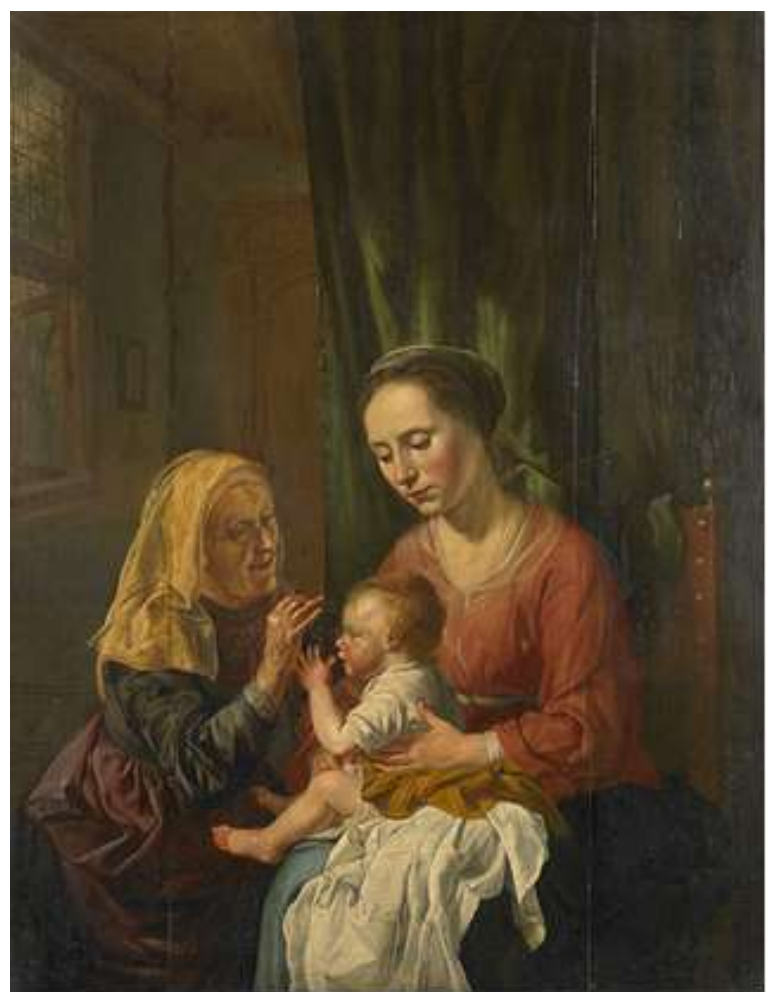

Fig. 5. Dirk Van Hoogstraten, Virgen y Niño con Santa Ana, 1630.

Fuente: www.rijksmuseum.nl

Los prejuicios que acompañaron a la vejez femenina parecen resurgir desde el momento en que esta Ana anciana pierde un lugar activo y jerárquico en las composiciones que la muestran junto a su hija y nieto. Simultáneamente, María ya no vuelve a ser representada como una niña, ni ella ni el niño vuelven a ser sostenidos por Ana.

La talla del Museo Nacional manifiesta un momento álgido del culto, cuya riqueza permitió que una pluralidad de ideas, interpretaciones y lecturas de Ana en conjunto con su descendencia, encontrara una forma concreta de materialización en la Santa Ana Triple.

$$
* * *
$$

\section{Fuentes}

Bacon, Roger. Opus Maius, BuRke, Robert (ed. y trad.), 1962, The Opus Majus of Roger Bacon, Nueva York, Russell, vol. II, p. 431.

${ }^{29}$ Virgen y Niño con Santa Ana ofreciéndole una manzana, 1516. De Young/Legion of Honor. Fine Arts Museums of San Francisco. 
María Laura Montemurro, La Santa Ana Triple en el Museo Nacional de Bellas Artes de Buenos Aires: una propuesta interpretativa

El Evangelio de la Natividad de María , 1985, Evangelios Apócrifos, trad. de GonZÁLEZBlanco, Edmundo, Buenos Aires, Hispamericana.

El Evangelio del Pseudo Mateo, 1985, Evangelios Apócrifos, trad. de GonZÁLEZ-BLANCO, Edmundo, Buenos Aires, Hispamericana.

\section{Bibliografía}

BECKER, Denise, 2005, “Anne, sainte ou sorcière?”, Autrement Mutations, N 236, pp. 68 77.

BIERNOFF, Suzannah 2002, Sight and Embodiment in the Middle Ages, Nueva York, Palgrave Macmillan, p. 264.

MiEZSKOWSI, Gretchen 2007, "Old Age and medieval misogyny: the old woman", en Classsen, Albrecht (ed), Old Age in the Middle Ages and the Rennaissance: interdisciplinary approaches to a neglected topic, Berlin Walter de Gruyter, pp. 299319.

NiXON, Virginia, 2004, Mary's mother. Saint Anne in late medieval Europe, The Pennsylvania University Press, Penssylvania, p. $216+40$ pl.

PERKInsOn, Stephen, 2009, The Likeness of the King: a prehistory of portraiture in late medieval France, Chicago, The University of Chicago Press, p. $352+96$ pl.

SAHAR, Shulamith 1996, "The old body in medieval culture", p.163, en KAY Sarah y RuBIN, Miri, Framing Medieval Bodies, Manchester-Nueva York, Manchester University Press, pp. 160-186.

SAHAR, Shulamith, 1997, Growing old in the Middle Ages. Winter clothes us in shadow and pain, Trad. de Yael Lotan, Londres y Nueva York, Routledge, p. 264.

SAHAR, Shulamith 1998, "Old age in the high and late Middle Ages", en JoHnson Paul y THANE, Pat, Old age from antiquity to post-modernity, Nueva York, Routledge, 1998, pp. 4363.

SAUTMAN, Francesca 1990, "Saint Anne in Folk Tradition", en AsHLEY, Kathleen y SheIngBorn, Pamela, Interpretating Cultural Symbols. Saint Anne in Late Medieval Society, Atenas y Londres, University of Georgia Press, pp. 6994.

SHEINGORN, Pamela 1990, "Appropiating the Holy Kinship. Gender and family history", en ASHLEY, Kathleen y SHEINGORN Pamela, Interpretating Cultural Symbols. Saint Anne in Late Medieval Society, Atenas y Londres, University of Georgia Press, pp. 169-198.

Viollet Le Duc, Eugène, 1858, Dictionnaire raissonné du mobilier francaise de l'èpoque carlovingienne á la Renaissance, Paris, Librarie Gründ et Maguet, vol. III, p. 479.

WALKER BYNUM, Carolyne 1995, The Resurrection of the Body in Western Christianity, 200-1336, Nueva York, Columbia University Press, p. 384+ 35 pl.

Walker Bynum, 2011, Christian Materiality. An Essay on Religion in Late Medieval Europe, Nueva York, Zone Books, p. $440+30$ pl.

WIRTH, Jane, 2003, "Sainte Anne est une sorcière", en WIRTH, Jean, Sainte Anne est une sorcière et autres essais, Droz, Ginebra, 2003, pp. 69-212.

WogAn-Browne, Jocelyn 1994, "Chaste bodies: frames and experiences", en KAY Sarah y RUBIN MiRi Miri (eds), 1994, Framing Medieval Bodies, Manchester University Press, Manchester y Nueva York, pp. 24-42. 